\title{
The Effect of Cellulose Acetate in the Inhibition of Bacteria: an Alternative for Antimicrobial Resistance
}

\author{
ILEANA NICHITA ${ }^{1 *}$, LAVINIA LUPA ${ }^{2}$, RADU VALENTIN GROS ${ }^{1}$, AURELIA VISA ${ }^{3}$, \\ ADRIANA POPA ${ }^{3 *}$, IULIA BUCUR ${ }^{1}$, EMIL TIRZIU ${ }^{1}$ \\ 1"Banat" University of Agricultural Science and Veterinary Medicine, 119 Calea Aradului, 30465, Timisoara, Romania \\ ${ }^{2}$ Faculty of Industrial Chemistry and Environmental Engineering, Politehnica University of Timisoara, 6 Vasile Parvan Blvd., \\ 300223, Timisoara, Romania \\ 3“'Coriolan Dragulescu”'Institute of Chemistry, 24 Mihai Viteazul Blvd., 300223, Timisoara, Romania
}

\begin{abstract}
Cellulose acetate (CA) is one of the most important esters of cellulose and it was analyzed by means of Fourier transform infrared spectroscopy (FT-IR), scanning electron microscopy (SEM) and EDX spectra. The FT-IR spectrum presented both the $C=O$ and $C-O$ stretching bands for acetyl groups. The EDX spectrum confirms the presence of $C$ and $O$ elements. The SEM image presented a spongy structure that is important for many applications. The antimicrobial properties of cellulose acetate solutions in acetic acid were determined in tests on two gram-negative species (Pseudomonas aeruginosa - ATCC 27853 and Escherichia coli - ATCC 25822), two gram-positive species (Staphylococus aureus - ATCC 29213 and Streptococcus pyogenes - ATCC 19615) and yeast species (Candida albicans - ATCC 10231). We have shown that samples of cellulose acetate solutions in acetic acid can be used to fight microbial and fungal infections. Of the gram-positive species tested, the strongest antimicrobial effect was observed against $S$. aureus. The diameter of inhibition zones of cellulose acetate solutions in acetic acid (P1 and P2) for $S$. aureus far exceeded inhibition zone both of reference substance (gentamicin) and of acetic acid solutions (M1 and M2), given values between 3.15 $\mathrm{cm}(P 1)$ and $3.55 \mathrm{~cm}(P 2)$. Also, the results suggested that the studied solutions (P1 and P2) had an antimicrobial effect pronounced for gram-negative species as $P$. aeruginosa, in which the P1 sample gave an inhibition zone of $2.95 \mathrm{~cm}$, and the P2 sample achieved an inhibition of $3.15 \mathrm{~cm}$. So, the antimicrobial activity of cellulose acetate solutions tested in vitro had a good antimicrobial effect, proportional to the concentration of the active substance.
\end{abstract}

Keywords: cellulose acetate, acetic acid, antimicrobial resistance, bacteria, antibiotic.

\section{Introduction}

In recent years, antimicrobial resistance has become a serious public health problem [1, 2]. As a result, microbial contamination in hospitals and the development of drug resistance to various pathogenic bacteria (gram-negative and gram positive) have become a major cause of mortality. That is why, investigations into this problem and a search for solutions have been presented in many scientific articles [3-5]. It should be noted that, the researchers' attention in recent years [6-8] has been focused on finding chemically modified polymeric supports with biologically active groups which have antimicrobial properties. Polymeric biocides obtained by the chemical bonding of antimicrobial active groups on insoluble polymers have attracted a lot of interest due to the fact that they can be recovered and used for a longer period of time. In previous studies amino(hydroxy)phosphonic acid groups were functionalised onto styrene-divinylbenzene type polymeric materials and they had a decisive antimicrobial role [9, 10]. Antimicrobial polymers which are of the natural type are a significant alternative to man-made products with potential for application in many areas of human activity [11, 12]. Biopolymers are environmentally friendly bio-based materials made from renewable raw resources and which can be re-used [13]. A biopolymer is cellulose. It is one of the most widespread organic compounds in the world, produced mainly by plants. Semi-synthetic derivatives have been obtained from cellulose, which is widely used in the pharmaceutical and cosmetic industries.

\footnotetext{
*email:nichita_ileana@yahoo.com; apopa_ro@yahoo.com,apopa@acad-icht.tm.edu.ro
} 
Cellulose derivatives are used in different types alone or in combination with other polymers, in different forms (e.g. films, membranes or fibers) [14], and different formulations prepared (e.g. buccal, ocular, vaginal, nasal and transdermal) in drug delivery systems [15]. A semi-synthetic derivative of cellulose would be cellulose acetate (CA), which is an ester of organic cellulose, which has uses in commercial products or in pharmaceutical investigations [16]. Thus, cellulose acetate (CA) is widely used for the preparation of semi-permeable, microporous and $\mathrm{pH}$ sensitive membranes [16].

The aim of this work was to integrate cellulose acetate and acetic acid into a simultaneous utilization to assess the antimicrobial efficacy and to show their effective use together. The study employed the cellulose acetate because it is a biodegradable and environmentally friendly material and with applications as a good drug delivery medium. The acetic acid is known to be used since old times against pathogen agents. The efficiency of the use of cellulose acetate solution in acid acetic was established for the antimicrobial evaluation against two gram-negative species (Pseudomonas aeruginosa - ATCC 27853 and Escherichia coli - ATCC 25822), two gram-positive species (Staphylococcus aureus - ATCC 29213 and Streptococcus pyogenes - ATCC 19615) and a species of yeast (Candida albicans -ATCC 10231). The study got a good incorporation of the cellulose acetate and acetic acid and brought synergistic effect in antimicrobial actions. Obtained results offer improving research and give a good method for antimicrobial assay with using cellulose acetate solution in acetic acid.

\section{Experimental part}

\subsection{Materials and apparatus}

The following reagents were used for the preparation of cellulose acetate solutions (dissolved in glacial acetic acid and distilled water): cellulose acetate (cellulose acetate pure company ROTH, CAS number $9004-35-7$, density $1.3 \mathrm{~g} / \mathrm{cm}^{3}$; acute toxicity: oral LD50>5050 mg/kg rat); $100 \%$ glacial acetic acid (Merck, 607-002-00-6, molar mass $60.05 \mathrm{~g} / \mathrm{mol}$ ). For antimicrobial testing, catalogue bacterial strains from two gram-negative bacterial species Pseudomonas aeruginosa - ATCC 27853 and Escherichia coli - ATCC 25822), two gram-positive species (Staphylococus aureus - ATCC 29213 and Streptococcus pyogenes - ATCC 19615) and a representative of the yeast group (a strain of Candida albicans - ATCC 10231) were used.

The FTIR spectrum (performed on $\mathrm{KBr}$ pills) of the cellulose acetate was recorded using the Jasco FTIR spectrophotometer (JASCO, Japan) in the range 4000-400 $\mathrm{cm}^{-1}$. The surface morphology of the cellulose acetate was studied by scanning electron microscopy (SEM) using a Quanta FEG 250 microscope equipped with an EDX ZAF detector (FEI Company, Netherlands).

The antimicrobial effect was determined by the agar diffusion disc method (according to the Standard Norms for Testing the Antimicrobial Sensitivity of Impregnated Discs) using impregnated discs [17].

\subsection{Preparation of the solutions of cellulose acetate}

P1 sample: $2 \%(\mathrm{w} / \mathrm{v})$ cellulose acetate

In $40 \mathrm{~mL}$ solution $(30 \mathrm{~mL}$ acetic acid and $10 \mathrm{~mL}$ distilled water, volume ratio 3:1), $0.8 \mathrm{~g}$ of cellulose acetate was dissolved. To obtain complete dissolution of the cellulose acetate the solution was heated slightly about $40{ }^{\circ} \mathrm{C}$.

P2 sample: $2.13 \%(\mathrm{w} / \mathrm{v})$ cellulose acetate

In $37.5 \mathrm{~mL}$ solution $(22.5 \mathrm{~mL}$ acetic acid and $15 \mathrm{~mL}$ distilled water, volume ratio $1.5: 1), 0.8 \mathrm{~g}$ cellulose acetate was dissolved. For complete dissolution of cellulose acetate, the solution was heated slightly about $40^{\circ} \mathrm{C}$.

\subsection{Preparation of the control solutions (M1 and M2) for tested solutions (P1 and P2)}

M1 control for P1 sample: a solution in the volume ratio 3:1 $(9 \mathrm{~mL}$ glacial acetic acid, $3 \mathrm{~mL}$ of distilled water) was prepared;

M2 control for P2 sample: a solution in the volume ratio 1.5:1 (9 mL glacial acetic acid, $6 \mathrm{~mL}$ of distilled water) was prepared. 


\subsection{Experimental tests of the antimicrobial activity}

The cellulose acetate solutions P1 and P2 were tested for antimicrobial activity along with the corresponding control solutions M1 and M2 (produced with the same dilutions as were used with the active substance (cellulose acetate) in $\mathrm{P} 1$ and $\mathrm{P} 2$ respectively).

The microbial strains chosen in this experiment, were two Gram negative bacterial species Pseudomonas aeruginosa - ATCC 27853 and Escherichia coli - ATCC 25822) and two Gram positive species (Staphylococus aureus - ATCC 29213 and Streptococcus pyogenes - ATCC 19615) and one yeast species, Candida albicans (ATCC 10231). Initially, $24 \mathrm{~h}$ cultures were prepared. Petri dishes with nutrient agar were inoculated with each of the microbial strains, using a sterile bacteriological loop to obtain isolated colonies on each dish. These colonies were incubated at $37^{\circ} \mathrm{C}$ for $24 \mathrm{~h}$. From the resulting cultures, an isolated colony was sterile taken and was inoculated into $10 \mathrm{~mL}$ broth (liquid culture medium, consisting of: peptone; $10 \mathrm{~g}$; $\mathrm{NaCl} 5.0 \mathrm{~g}$; meat extract $5.0 \mathrm{~g}$ in $1000 \mathrm{~mL}$ of sterile distilled water; $p \mathrm{H}=6.8$ ). These tubes with the inoculated broth were also incubated for $24 \mathrm{~h}$ with the thermostat at $37^{\circ} \mathrm{C}$. These microbial cultures were considered to be fresh and pure cultures and were used for tests. To obtain the pure culture of Candida albicans a similar procedure was performed, but the culture medium used was Sabouraud, and the incubation was carried out at $25^{\circ} \mathrm{C}$ for $48 \mathrm{~h}$.

To perform the tests from each species cultures, broth was prepared with a cell density of $1.5 \times 10^{8}$ $\mathrm{CFU} / \mathrm{mL}$, corresponding to an optical density of 0.5 on the McFarland scale. These bacterial and yeast dilutions were tested using the agar disk diffusion method. In order to actually test the antimicrobial activity, the culture media, nutritive agar and Sabouraud medium were poured into sterile Petri dishes, using one plate for each species. After the medium in each dish had solidified, the condensation which formed on plate cover was eliminated by holding the plates in the thermostat for $15 \min \left(37^{\circ} \mathrm{C}\right)$.

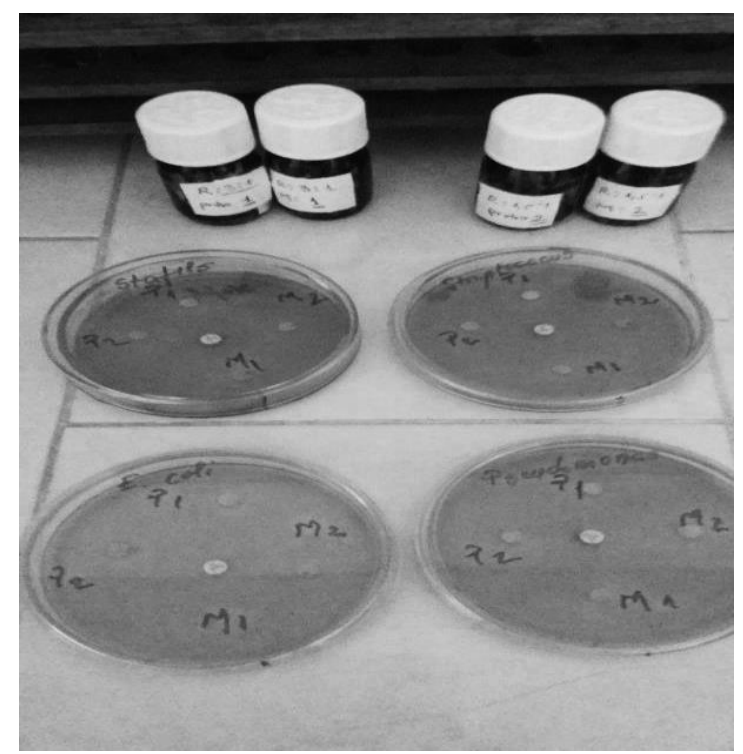

Figure 1. Petri dishes with microbial cultures and with the tested solutions (P1, P2, M1 and M2) by the disk diffusion method

Filter paper discs (about $6 \mathrm{~mm}$ in diameter) pre-impregnated with $10 \mu \mathrm{L}$ of each sample (P1 and P2) and of the control solutions (M1 and M2) were then placed on the surface of the nutritive culture medium. Also, on each plate with bacteria inoculums, a disc impregnated with the antibiotic, Gentamicin was placed, and for the yeast culture, nystatin was used. This was done to produce a comparative assessment of the antimicrobial effect (Figure 1).

The antimicrobial effect was assessed by measuring the diameter of the inhibition grow zone formed around the discs (including the paper disc $-0.6 \mathrm{~cm}$ ). Determinations were performed three times, obtaining the average of the inhibition zones. 


\section{Results and discussions}

\subsection{The characterization of cellulose acetate used for the antimicrobial study}

The cellulose acetate has a structural uniformity by type $\beta$-1-4-linked polyglucan (Figure 2 ).

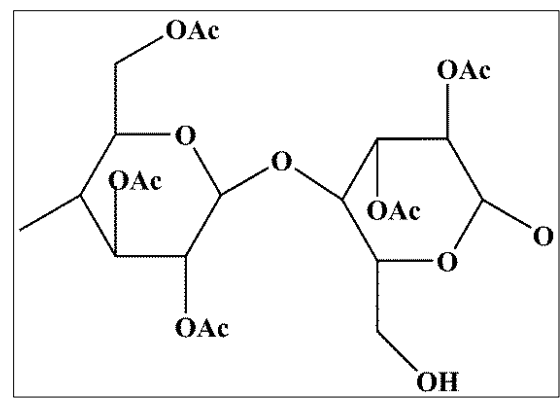

Figure 2. Structure of the cellulose acetate, where: Ac - acetyl group

In order to assess the use of cellulose acetate as an antimicrobial agent we have presented its analysis by EDX Quantification, SEM image and FTIR spectra.

The result of EDX analysis of the cellulose acetate (Table 1) indicated the presence of elements C and $\mathrm{O}$ in its structure.

Table 1. EDX Quantification (Standardless)

\begin{tabular}{ccc}
\multicolumn{3}{c}{ of the cellulose acetate } \\
\hline Sample & \multicolumn{2}{c}{ Cellulose acetate } \\
\cline { 2 - 3 } /Elem. & $\mathrm{Wt} \%$ & At \% \\
\hline $\mathrm{C}$ & 49.66 & 56.78 \\
\hline $\mathrm{O}$ & 50.34 & 43.22 \\
\hline
\end{tabular}

The cellulose acetate had a spongy structure (Figure 3), potentially important for its application in the fields of medical and food production.

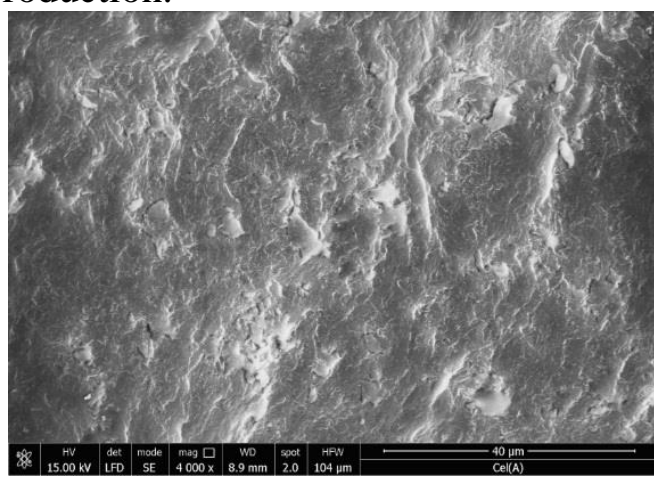

Figure 3. SEM image of cellulose acetate

FTIR spectrum indicates some characteristic functional groups (Figure 4) that confirm the formation of cellulose acetate [18]. A band at $3440 \mathrm{~cm}^{-1}$ is caused by $\mathrm{O}-\mathrm{H}$ stretching. Both the absorption band at $1737 \mathrm{~cm}^{-1}$ for $\mathrm{C}=\mathrm{O}$ stretching and peak at $1240 \mathrm{~cm}^{-1}$ for $\mathrm{C}-\mathrm{O}$ stretching are consistent with acetyl groups. The absorption peak at $1320 \mathrm{~cm}^{-1}$ was attributed to $\mathrm{CH}_{3}$ vibration in the acetyl group. 


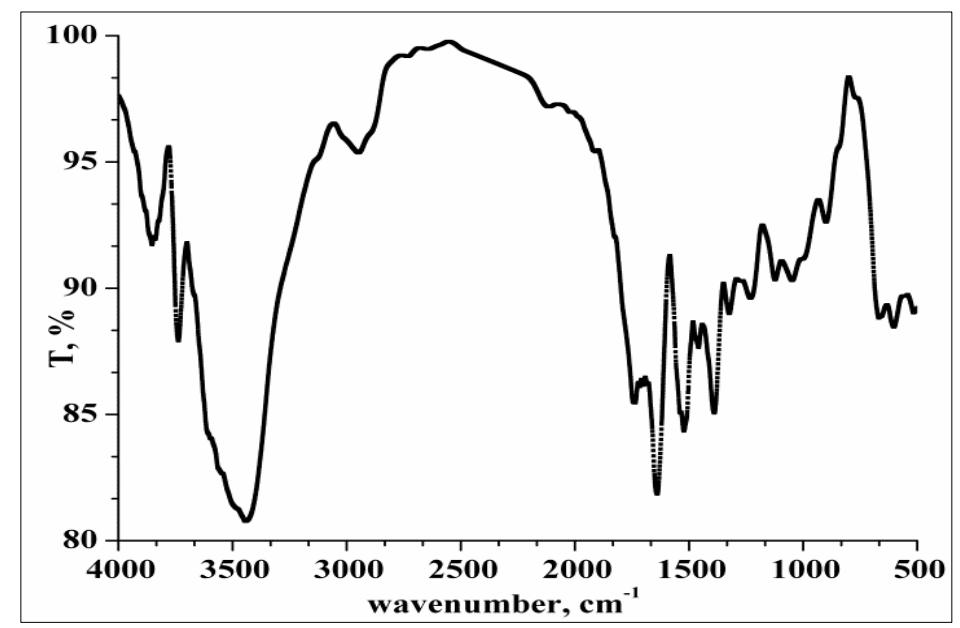

Figure 4. FTIR spectra of cellulose acetate

\subsection{Testing the antimicrobial activity}

The antimicrobial activity of samples P1, P2 (cellulose acetate solutions), M1 and M2 (the control solutions) was tested by the agar disk diffusion method and the results are presented in Table 2 and Figure 5. Diameters of the inhibition zones (in $\mathrm{cm}$ ) that indicated antimicrobial activity of the tested solutions and antibiotics, and their values are shown in Table 2. Comparisons in antimicrobial activity are shown as a percentage in Figure 5.

Table 2. Diameters of the microbial inhibition areas of samples P1, P2, M1 and M2

\begin{tabular}{cccccc}
\hline \multirow{2}{*}{ Microbial species tested } & \multicolumn{5}{c}{ Diameter of the inhibition zone (cm) } \\
\cline { 2 - 6 } & $\begin{array}{c}\text { Antibiotic/ } \\
\text { antifungal disc }\end{array}$ & Disc with P1 & Disc with M1 & Disc with P2 & $\begin{array}{c}\text { Disc with } \\
\text { M2 }\end{array}$ \\
\hline Pseudomonas aeruginosa & 2.3 & 2.95 & 2.25 & 3.15 & 2.15 \\
\hline Escherichia coli & 2.1 & 2.15 & 1.85 & 2.45 & 1.95 \\
\hline Staphylococcus aureus & 2.4 & 3.15 & 2.40 & 3.55 & 2.65 \\
\hline Streptococcus pyogenes & 2.3 & 2.85 & 2.35 & 3.35 & 2.35 \\
\hline Candida albicans & 2.0 & 2.75 & 2.45 & 2.9 & 2.45 \\
\hline
\end{tabular}

It was found that all the tested solutions, both the samples containing cellulose acetate and the corresponding control samples, produced inhibition zones for bacterial and the yeast growth. In the case of samples containing cellulose acetate, these inhibition zones were even greater or approximately equal to those obtained with the antibiotic disc, or the antimycotic ones. The acetic acid solutions (M1 and M2), used as controls, also had an antimicrobial effect, but in all tested species this effect was less than that produced by the cellulose acetate samples. Of the gram-positive species tested, the strongest antimicrobial effect was observed against Staphylococcus aureus, with the sample P1 giving a $3.15 \mathrm{~cm}$ inhibition zone, and the sample P2 a zone of $3.55 \mathrm{~cm}$.

Of the gram-negative species tested, the antimicrobial effect was more pronounced for Pseudomonas aeuginosa, in which the P1 sample gave an inhibition zone of $2.95 \mathrm{~cm}$, and the P2 sample achieved an inhibition of $3.15 \mathrm{~cm}$. Compared to the other two species, the P1 sample, with $2 \%$ cellulose acetate, formed a inhibition zone of $2.15 \mathrm{~cm}$ against Escherichia coli and $2.85 \mathrm{~cm}$ against Streptococcus pyogenes. The $\mathrm{P} 2$ sample with $2.13 \%$ cellulose acetate induced an inhibition zone of $2.45 \mathrm{~cm}$ for $E$. coli and $3.35 \mathrm{~cm}$ for $S$. pyogenes. For the yeast specie tested, Candida albicans, the diameter of the inhibition zones was relatively close in value for both cellulose acetate samples, namely $2.75 \mathrm{~cm}$ for the P1 sample, with $2 \%$ cellulose acetate and $2.9 \mathrm{~cm}$ for the P2 sample, with a cellulose acetate content of $2.13 \%$. 


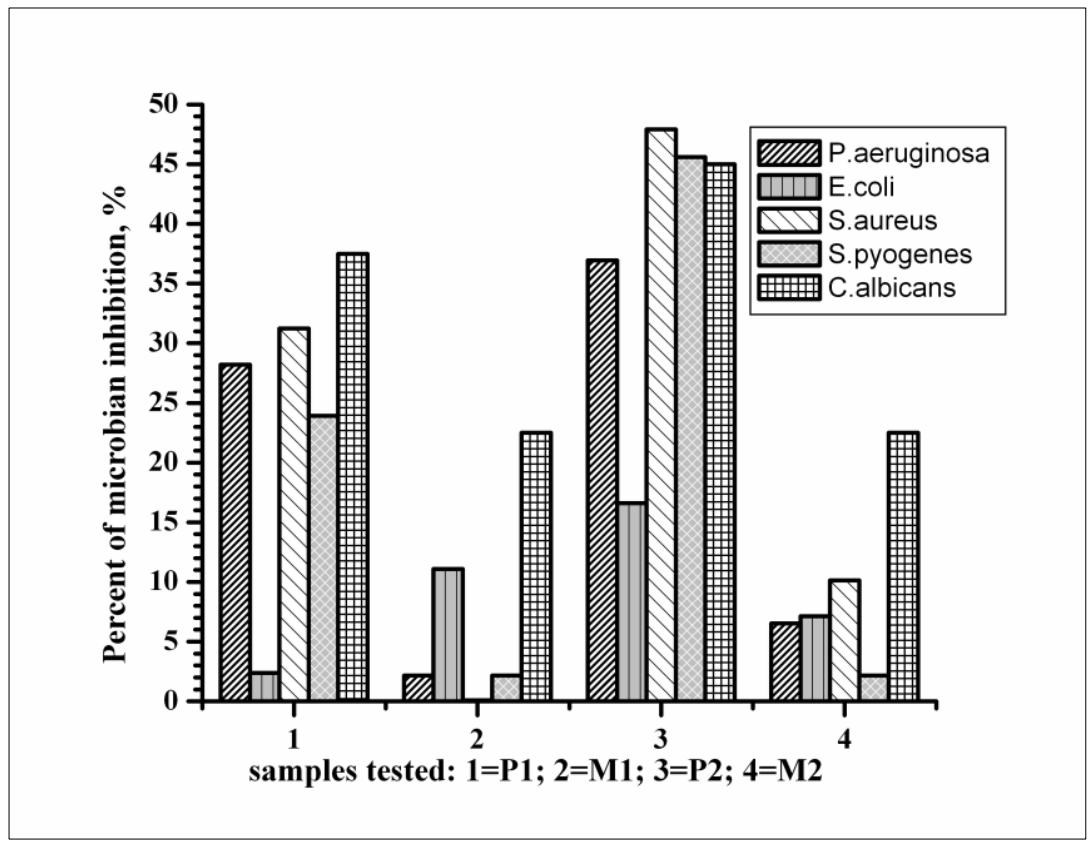

Figure 5. Percent of microbial inhibition (\%) of samples tested versus antimicrobial culture

A comparison between data for the antimicrobial action of the solutions tested (P1 and P2) and the antibiotic and the antimycotic used, is shown in Figure 5. The P2 cellulose acetate solution with a concentration of $2.13 \%$ compared to the antibiotic used (Gentamicin) had a 36.95\%, higher antimicrobial effect against the Pseudomonas aeruginosa species and a $47.91 \%$ greater effect against Staphylococus aureus. Also, the antimicrobial effect of this $\mathrm{P} 2$ solution was greater than that of the antibiotic when used against the other bacterial species used for testing. Against the Streptococcus pyogenes species, the antibacterial effect was $45.6 \%$ higher, but against Escherichia coli, the cellulose acetate solution P2 acted with an antibacterial effect of $16.6 \%$. The antifungal effect against Candida albicans of the same solution (P2 - cellulose acetate $2.13 \%$ ) was $45 \%$ higher compared to the antifungal drug used (nystatin).

The results of studies published so far show that cellulose acetate acquires antimicrobial activity dependent on the substance with which it is associated, and that this polymer is insoluble in water, but soluble in various solvents such as acetone, acetic acid, methanol, dimethyl acetamide, dimethylformamide, etc [19-21].

The novelty of this research consists in using cellulose acetate in combination with acetic acid in a antimicrobial study. Acetic acid was used, considering that it is a good solvent for cellulose acetate with the degree of substitution (DS) greater than $0.8[14,22,23]$ and that its antimicrobial effect has long been known. So far, there are studies on the antimicrobial effects both for cellulose acetate and acetic acid, but they have been tested separately.

The antibacterial effect of acetic acid has often been investigated with the idea that it can be used as an antimicrobial agent in the poultry, beef or pork meat industry, in order to decontaminate and extend the shelf life of products and to control bacteria, such as Salmonella spp. or Escherichia coli [24].

The acetic acid solutions (M1 and M2 - control solutions) used in this study have presented an antimicrobial effect versus E. coli.; it was observed that the antimicrobial effect was higher in the case of the cellulose acetate solutions in acetic acid (P1 and P2 - tested solutions), exceeding even the effect of the antibiotic (Gentamicin) used as a reference substance.

In literature have been presented study on the antimicrobial activity of acetic acid on some antibiotic resistant bacteria strains such as Streptococcus spp., Staphylococcus aureus, E. coli, Pseudomonas aeruginosa and Proteus spp. [25]. For this, the diffusion method was used and different concentrations of acetic acid $(0.5 \%, 1 \%, 1.5 \%, 2 \%$ and $2.5 \%)$. At all concentrations tested, acetic acid was found to be 
able to inhibit bacterial growth. Even at the low concentration of $0.5 \%$ acetic acid, a bacterial inhibition zone from $1.3 \mathrm{~cm}$ to $1.8 \mathrm{~cm}$ was obtained. At higher concentrations of $1 \%$ and $1.5 \%$, the inhibition zone ranged from $2 \mathrm{~cm}$ to $2.2 \mathrm{~cm}$ respectively [25]. In our investigation were used same bacteria species that were described by Pundir and Pranay [25]. Also, it was observed the inhibition zone of acid acetic solutions (M1 and M2) which ranges between $1.85 \mathrm{~cm}$ (in E. coli) and $2.65 \mathrm{~cm}$ (in S. aureus), but the cellulose acetate solutions in acid acetic have more pronounced effect. The inhibition zones were as follows: for P1 between $2.15 \mathrm{~cm}$ and respectively $2.45 \mathrm{~cm}$ against $E$. coli and for the $\mathrm{P} 2$ was obtained $3.15 \mathrm{~cm}$ and respectively $3.55 \mathrm{~cm}$ against $S$. aureus.

Raftari et al. [26] reported that the action of acetic acid against the $S$. aureus is more pronounced than that against E. coli, at the tested concentrations of $1 \%, 1.5 \%$ and $2 \%$. They also found that the inhibitory effect of bacterial growth was lower in Clostridium spp. The present study, the acetic acid solutions tested against $S$. aureus have shown a good antibacterial activity, similar or even higher than the antibiotic used as reference substance (gentamicin) and having the inhibition zone between $2.4 \mathrm{~cm}$ (M1) and $2.65 \mathrm{~cm}$ (M2). Instead, it has been remarked that the antibacterial activity of cellulose acetate solutions in acetic acid far exceeded the activity both of reference substance (gentamicin) and of acetic acid solutions (M1 and M2), given an inhibition zone between $3.15 \mathrm{~cm}(\mathrm{P} 1)$ and $3.55 \mathrm{~cm}(\mathrm{P} 2)$.

Thus, Liakos et al. [27, 28], using cellulose acetate fibers impregnated with essential oils from various aromatic herbs, tested the antimicrobial effect against $S$. aureus, E. coli, and C. albicans. Cellulose acetate fibers containing cinnamon, lemongrass and peppermint oils indicated high antimicrobial activity against $E$. coli and $C$. albicans. Also, Anitha et al. [29] have tested fibrous membrane of cellulose acetate impregnated with $\mathrm{ZnO}$ against methicillin-resistant $S$. aureus (MRSA), E. coli and Citrobacter freundii. Significant inhibition zones were observed for $\mathrm{ZnO}$ embedded CA. The diameters of these inhibition zones around the membranes were $27 \mathrm{~mm}, 22 \mathrm{~mm}, 14 \mathrm{~mm}$ for methicillinresistant S. aureus (MRSA), E. coli and Citrobacter freundii, respectively. In this paper, the P1 and P2 solution showed similar and even better results compared to the $\mathrm{ZnO}$-impregnated cellulose acetate fibrous membrane, which was studied by Anitha et al. [29]. For S. aureus the diameters of inhibition zone were $3.15 \mathrm{~cm}$ at $\mathrm{P} 1$ and $3.55 \mathrm{~cm}$ for P2, respectively. Also, for E. coli the diameters of the inhibition zone for sample $\mathrm{P} 2$ and $\mathrm{P} 1$ were $2.45 \mathrm{~cm}$ and $2.15 \mathrm{~cm}$, respectively.

Cellulose acetate currently is the most commonly used as biopolymer and has multiple uses in the pharmaceutical industry and in medicine because it is stable, biocompatible and bioresorbable. Thus, studies on the antimicrobial effect of cellulose acetate solutions in acetic acid are of great relevance and importance $[15,16]$.

\section{Conclusions}

The results of in vitro tests on the antimicrobial activity indicated that cellulose acetate solutions in acetic acid had a good antimicrobial effect, proportional to the concentration of the active substance. The results suggested that the antimicrobial effect of the solutions studied was superior to that given by the antibiotic and antifungal agents. The acetic acid used as a solvent for cellulose acetate had an antibacterial effect close to that of the antibiotic / antimycotic used, but much lower than that of the cellulose acetate samples (P1, P2). The results shown that the solutions studied had an increased antimicrobial effect against microorganisms compared to acetic acid. From the observed antimicrobial effect of samples P1 and P2, it has been demonstrated that they can be used to counter microbial and fungal infections. Future research should be undertaken to establish the minimum inhibitory concentration of the two solutions and to highlight their potential for application in the medical field.

Acknowledgments: The authors are grateful for: biopolymer (cellulose acetate) which was obtained by partial financial support from Program no. 2 of Coriolan Dragulescu Institute of Chemistry, Timisoara. 


\section{References}

1.BANCIU, A.R., IONESCU, L., IONICA, D.L., MITRU, D., NITA-LAZAR, M., Efficiency of biocides on the aquatic systems through bacterial model, Rev.Chim., 71(1), 2020, 57-60, https://doi.org/10.37358/RC.20.1.7811.

2. SALA, C., MORAR, A., TIRZIU, E., NICHITA, I., IMRE, M., IMRE, K., Environmental Occurrence and Antibiotic Susceptibility Profile of Listeria monocytogenes at a Slaughterhouse Raw Processing Plant in Romania, Journal of Food Protection, 79(10), 2016, 1794-1797, https://doi.org/ 10.4315/0362028X.JFP-16-052.

3.CALINESCU, M., STOICA, C., NITA-LAZAR, M., Complex compounds of Sm (III) with chlorhexidine synthesis, characterization, luminescent properties and antibacterial activity, Rev.Chim., 70(1), 2019, 6-12.

4. VARASTEANU, D., CHICAN, I., DONCEA, S.M., RAUT, I., CALIN, M., JECU, L., Nickel (II) and cobalt (II) complexes of some amino acid-based surfactants with antimicrobial activity, Rev.Chim., 70(2), 2019, 361-364.

5. BUCUR, I., DUMITRESCU, V., IMRE, K., HERMAN, V., NICHITA, I., CRISTINA, R.T., TIRZIU, E. Research on the frequency of resistance phenotypes in bacterial strains isolated from chamois (Rupicapra rupicapra carpatica), Revista Romana de Medicina Veterinara, 30(1), 2020, 66-70.

6. CHOUBEY, R., CHOUHAN, R., BAJPAI, J., BAJPAI, A.K., Facile synthesis of silver hydroxyapatite (AgHAP) reinforced nanocomposites of poly (styrene)-poly (methyl methacrylate) and study of their mechanical and blood-compatible behavior, ChemistrySelect, 4(37), 2019, 10983-10994, https://doi.org/10.1002/slct.201902351.

7. DZHARDIMALIEVA, G.I., UFLYAND, I.E., Synthetic methodologies for chelating polymer ligands: Recent advances and future development, ChemistrySelect, 3(46), 2018, 13234-13270, https://doi.org/10.1002/slct.201802516.

8. MUNOZ-BONILLA, A., FERNANDEZ-GARCIA, M., Polymeric materials with antimicrobial activity, Prog. Polym. Sci., 37(2), 2012, 281-339, https://doi.org/10.1016/j.progpolymsci.2011.08.005. 9. NICHITA, I., POPA, A., DRAGAN, E.S., ILIESCU, S., ILIA, G., Grafted $\alpha$-hydroxyphosphonic acids onto polymeric supports: preparation, characterization, and antimicrobial effect, J. Biomater. Sci. Polym. Ed., 26(8), 2015, 483-496, https://doi.org/10.1080/09205063.2015.1030990.

10. NICHITA, I., LUPA L., STOIA, M., DRAGAN, E.S., POPA, A., Aminophosphonic groups grafted onto the structure of macroporous styrene-divinylbenzene copolymer: preparation and studies on the antimicrobial effect, Polym. Bull., 76, 2019, 4539-4557, https://doi.org/10.1007/s00289-018-2613-6.

11. XUE, Y., XIAO, H., ZHANG, Y., Antimicrobial polymeric materials with quaternary ammonium and phosphonium salts, Int. J. Mol. Sci., 16, 2015, 3626-3655, https://doi.org/10.3390/ijms1 6023626.

12. MUNOZ-BONILLA, A., ECHEVERRIA, C., SONSECA, Á., ARRIETA, M.P., FERNANDEZGARCIA, M., Bio-Based Polymers with antimicrobial properties towards sustainable development, Materials, 12, 2019, 641, https ://doi.org/10.3390/ma12040641.

13. SHAGHALEH, H., XU, X., WANG, S., Current progress in production of biopolymeric materials based on cellulose, cellulose nanofibers, and cellulose derivatives, $R S C A d v$., 8, 2018, 825-842, https://doi.org/10.1039/c7ra11157f.

14. FISCHER, S., THU-MMLER, K., VOLKERT, B., HETTRICH, K., SCHMIDT, I., FISCHER, K., Properties and applications of aellulose acetate, Macromol. Symp., 262, 2008, 89-96.

15. VLAIA, L., CONEAC, G., OLARIU, I., VLAIA, V., LUPULEASA, D., Cellulose-derivatives-based hydrogels as vehicles for dermal and transdermal drug delivery, in Emerging Concepts in Analysis and Applications of Hydrogels, Ed. Sutapa Biswas Majee, IntechOpen, 2016, 159-199,

https://doi.org/10.5772/63953.

16. SHOKRI, J., ADIBKIA, K., Application of cellulose and cellulose derivatives in pharmaceutical industries, in: Cellulose - Medical, Pharmaceutical and Electronic Applications, Ed. Theo G.M. Van De Ven, IntechOpen, 2013, 48-66, https://doi.org/10.5772/55178. 
17. BALOUIRI, M., SADIKI, M., IBNSOUDA, S. K., Methods for in vitro evaluating antimicrobial activity: A review, J. Pharm. Anal., 6(2), 2016, 71-79, https://doi.org/10.1016/j.jpha.2015.11.005.

18. FEI, P., LIAO, L., CHENG, B., SONG, J., Quantitative analysis of cellulose acetate with a high degree of substitution by FTIR and its application, Anal. Methods, 9, 2017, 6194-6201, https://doi.org/10.1039/c7ay02165h.

19. LIU, H., TANG, C., Electrospinning of cellulose acetate in solvent mixture N,N-dimethylacetamide (DMAc)/acetone, Polym. J., 39(1), 2007, 65-72, https://doi.org/10.1295/polymj.PJ2006117.

20. ZHOU, W. T., HE, J. X., CUI, S. Z., GAO, W. D., Preparation and properties of electrospun cellulose acetate nanofiber mats, Adv. Mat. Res., 148-149, 2011, 1408-1412,

https://doi.org/10.4028/www.scientific.net/AMR.148-149.1408.

21. RODRIGUEZ, K., GATENHOLM, P., RENNECKAR, S., Electrospinning cellulosic nanofibers for biomedical applications: structure and in vitro biocompatibility, Cellulose, 19, 2012, 1583-1598, https://doi.org/10.1007/s10570-012-9734-0.

22. LIU, H., HSIEH, Y.-L., Ultrafine fibrous cellulose membranes from electrospinning of cellulose acetate, J. Polym. Sci. Part B. Polym. Phys., 40, 2002, 2119-2129.

23. HAN, S.O., YOUK, J.H., MIN, K.D., KANG, Y.O., PARK, W.H., Electrospinning of cellulose acetate nanofibers using a mixed solvent of acetic acid/water: Effects of solvent composition on the fiber diameter, Mater. Lett., 62, 2008, 759-762, https ://doi.org/10.1016/j.matlet.2007.06.059.

24. SAKHARE, P.Z., SACHINDRA, N.M., YASHODA, K.P., Efficacy of intermittent decontamination treatments during processing in reducing the microbial load on broiler chicken carcass, Food Control, 10, 1999, 189-194, https://doi.org/10.1016/S0956-7135(99)00017-1.

25. PUNDIR, K.R., PRANAY, J., Evaluation of five chemical food preservatives for their antibacterial activity against bacterial isolates from bakery products and mango pickles, J. Chem. Pharm. Res., 3(1), 2011, 24-31.

26. RAFTARI M., JALILIAN F.A., ABDULAMIR A.S., Effect of organic acids on Escherichia coli O157:H7 and Staphylococcus aureus contaminated meat, Open Microbiol. J., 3, 2009, 121-127, https://doi.org/10.2174/1874285800903010121.

27. LIAKOS, I. L., HOLBAN, A. M., CARZINO, R., LAUCIELlO, S., GRUMEZESCU, A. M., Electrospun fiber pads of cellulose acetate and essential oils with antimicrobial activity, Nanomaterials, 7(4), 2017, 84, https://doi.org/10.3390/nano7040084.

28. LIAKOS, I., RIZZELlO, L., HAJIALI, H., BRUNETTI, V., CARZINO, R., POMPA, P., ATHANASSIOU, A., MELE, E., Fibrous wound dressings encapsulating essential oils as natural antimicrobial agents, J. Mater. Chem. B, 3(8), 2015, 1583-1589, https://doi.org/10.1039/C4TB01974A. 29. ANITHA, S., BRABU, B., THIRUVADIGAL, D.J., GOPALAKRISHNAN, C., NATARAJAN, T.S., Optical, bactericidal and water repellent properties of electrospun nano-composite membranes of cellulose acetate and $\mathrm{ZnO}$, Carbohyd. Polym., 87, 2012, 1065-1072, https://doi.org/10.1016/j.carbpol.2011.08.030.

$\overline{\text { Manuscript received: } 8.05 .2020}$ 